\title{
The Hippocratic Oath and Principles of Medical Ethics
}

\author{
Gilbert Berdine MD
}

The Hippocratic Oath is associated with the practice of medicine, but over time fewer medical graduates have taken any form of the Hippocratic Oath. As of 2006, the State University of New York Upstate Medical School in Syracuse was the only U.S. medical school that administered the classic version of the Hippocratic Oath to its graduates. The Hippocratic Oath has been revised to make it more acceptable to modern schools, but the medical profession no longer has a common set of promises that guide it. This article will look at the classic version of the Hippocratic Oath to see why it has been abandoned. Modern medical students wish to graduate into an ancient order of physicians, so they long for a solemn ceremony, but it is difficult to craft a solemn ceremony that remains agreeable to a diverse group of students.

The Hippocratic Oath has four parts: a pledge to pagan deities, a list of positive obligations, a list of negative obligations, and a concluding piety. Each section has ethical implications.

\section{Pledge to Pagan Deities}

Apollo Physician and Asclepius and Hygieia and Panacea and all the gods and goddesses, making them my witnesses, that I will fulfill according to my ability and judgment this oath and this covenant:

A pledge to a deity is the basis of a solemn promise. Ancient ethical systems were based on Divine-Command Theory. The distinction between right and wrong was derived from commands by a deity. A pledge to a deity is equivalent to a pledge to act

Corresponding author: Gilbert Berdine MD Contact Information: Gilbert.Berdine@ttuhsc.edu DOI: 10.12746/swrccc 2015.0309.115 morally right. This tradition remains in the modern era. "As God is my witness I hereby pledge to ..." can be found in modern rituals to stress the seriousness of purpose. Courts in the U.S. require prospective witnesses to pledge their truthfulness: "Do you solemnly swear or affirm that you will tell the truth, the whole truth, and nothing but the truth, so help you God?" This pledge becomes a source of contention in a multi-cultural society as some members believe in other deities.

Anyone who takes his or her religion seriously would not pledge to a pagan god as this would be a form of idolatry. This pledge is probably the main reason that the Oath has been abandoned in the modern era, but what can take its place as a symbol of seriousness of promise? To whom should modern graduates of medicine make their promise of purpose?

Modern ethical systems are deontological, or duty driven, in nature. Following the work of Kant, ethics have been based on reason from basic axioms of duty rather than from divine commands. Deontological ethical systems have no need for a pledge to a deity, but a pledge to follow some theory may not have the solemn nature of older rituals.

The distinction between positive and negative obligations is essential to understanding ethics. A positive obligation is something that one is REQUIRED to do. A negative obligation is something that one is FORBIDDEN from doing. The Hippocratic Oath includes both types of obligations. An ethical system will place obligations in a hierarchy such that some obligations trump others in cases of conflict. Failure to fulfill an obligation implies that a breach of contract or faith has occurred and that the offended party has a legal or moral claim against the offending party. 


\section{HONOR THY TEACHER}

To hold him who has taught me this art as equal to my parents and to live my life in partnership with him, ...

This portion of the Hippocratic Oath is a relic of the Master/Apprentice Model of training. The Master/ Apprentice system continued through the Medieval Period, but was gradually replaced by University systems and systems of state licensure. Both the master (teacher) and apprentice (student) had obligations to each other. There was either an explicit or implicit contract between them. The apprentice would learn from the master until the master graduated the apprentice with a letter of recommendation.

\section{Professional Courtesy} share of mine, ...

and if he is in need of money to give him a

Professional Courtesy was widely practiced in the U.S. when I trained (1978-1983). No physician would charge for services rendered to another physician or medical student, or to any family members of such. The change in attitude is largely due to the changing economic landscape of medical practice. In 1980, practitioners were in solo practice and set their own fees. With the changing nature of practice brought on by Medicare and the DRG system, practitioners became beholden to other masters and could no longer dictate what they charged to each client. Today, hospitals will protest that Professional Courtesy would be a violation of Stark Laws that view preferential treatment to colleagues as a form of kickback.

\section{Guild SeCRETS}

and to regard his offspring as equal to my brothers in male lineage and to teach them this art if they desire to learn it - without fee and covenant; to give a share of precepts and oral instruction and all the other learning to my sons and to the sons of him who has instructed me and to pupils who have signed the covenant and have taken an oath according to the medical law, but to no one else. (emphasis mine)

Greek society at the time of Hippocrates was patriarchal. Modern versions of the Hippocratic Oath are neutral with respect to sex and gender to conform to modern sensibilities.

Physicians belong to an ancient order. They are a trade guild or a cartel. Membership is strictly limited. One of the purposes for the Hippocratic Oath was to offset the privileges of guild membership with responsibilities to the public. This portion of the oath recognizes the privileges of guild membership and requires students to swear to keep guild secrets. The exclusive nature of professional membership is maintained in the modern era with state licensure. The stated purpose of licensure is to protect the public against charlatans, but the actual purpose of licensure is to ensure monopoly profits for guild members.

\section{Work to Aid Patients}

I will apply dietetic measures for the benefit of the sick according to my ability and judgment; ...

There are several ethical issues in this short passage. This is a positive obligation. A limitation of many positive obligations is that they are possible only within the constraint of available resources. Negative obligations do not have this limitation, since doing nothing is never impossible. Note in this passage the term, "according to my ability and judgment" which acknowledges that fulfillment may not always be possible.

Many physicians would agree that their duty is to their patients. In an ideal world, physicians would place the interest of their patients above their own interests, the interest of the hospital, and the interest of the government. It is difficult, if not impossible, to put the interests of your customers first if you are not compensated by your customers. Without compensation, one cannot practice for very long. Many modern oaths pledge to put the interest of the patient first, but public financing of health care puts the power of the 
purse in the hands of the government. When Medicare dictates that physicians will be compensated based on length of stay, which physician can put the interest of the patient above the interest of the hospital or government paying the physician?

\section{NON-MALEFICENCE}

\section{I will keep them from harm and injustice.}

In the classic version, this is stated as a positive obligation. It is very simple to state something similar as a negative obligation. Primum non nocere is the Latin phrase that translates "First do no harm." Although this phrase is widely associated with the Hippocratic Oath, it does not appear in the oath. The ancient origin of the phrase has been attributed to Hippocrates in another of his writings. The text Epidemics includes, "The physician must ... have two special objects in view with regard to disease, namely, to do good or to do no harm." The English version of the phrase is attributed to the British physician Thomas Sydenham in the 17th century.

Modern medical ethics consider four deontological principles: autonomy, justice, non-maleficence, and beneficence. Different ethical systems differ in how these principles are ranked in situations where the principles come into conflict with one another. For example, the principle of non-maleficence is a form of the libertarian non-aggression principle (NAP). The entire libertarian system of ethics can be derived from this single rule or axiom.

Alternate systems of ethics can be based on the Utilitarian Principle of the greatest good for the greatest number. The modern system of health care has moved in this direction. Utilitarian ethical systems usually include both positive and negative obligations. A Utilitarian system requires a calculation that compares the benefits and hazards of each possible action and chooses the action which has the most favorable total. This may sound good in principle, but this calculation requires comparisons between things that are not really comparable. Take, for example, a mandatory vaccination program. The program offers the benefit of herd immunity, but it carries the hazard of unwanted side effects of the vaccine. There is no universal way to compare death against property damage. A given person's calculation will depend on whether the death is of a loved one or of a complete stranger. Inevitably, one person's valuation is given greater weight than the valuations of everyone else.

Modern ethical systems can be either secular or religious. Religious systems continue to follow Divine-Command Theory. Religious ethical systems include consideration of autonomy, justice, non-maleficence and beneficence, but obedience to divine commands takes precedence over other duties. Although all the major modern religions have sacred texts which contain the divine commands, the Catholic Church has a single voice of authority over the interpretation of its text, and the Catholic Church has taken an official position, recorded in catechisms, on the issues mentioned in the Hippocratic Oath. The Catholic Church will be used as a reference point, because its official positions are readily available whereas the other mainstream religions have no easily available and official positions.

\section{EUTHANASIA}

I will neither give a deadly drug to anybody if asked for it, nor will I make a suggestion to this effect.

This is a negative obligation forbidding the practice of euthanasia. This is one area in which the ancient medical tradition is in agreement with the Catholic Church. The modern medical era has seen a shift in attitude more favorable to euthanasia. This negative obligation has been dropped from some of the modern versions of the Oath.

\section{Abortion} remedy.

Similarly I will not give to a woman an abortive

We see another negative obligation forbidding the practice of abortion. This is another area in which the ancient medical tradition is in agreement with the 
Catholic Church. Whereas the modern medical era has shifted somewhat towards the practice of euthanasia, abortion has seen a much larger shift to which a segment of medical practice is dedicated to abortion. Abortion is likely the most polarizing issue of our time. Even among those who call themselves libertarians, there is heated argument on this issue. Some libertarians consider the fetus to be a trespasser and leave the decision to the mother. Some libertarians consider the fetus to be an innocent bystander and consider abortion to be murder. Whether an Oath takes a permissive or proscriptive stance on abortion, a significant number of medical graduates would refuse to say the words.

\section{Fidelity to PRINCIPLE}

In purity and holiness I will guard my life and my art.

This is a positive obligation mixed in with the preceding negative obligations. It pledges to be true to the Oath regardless of consequences. The metaphor usually associated with this pledge is walking the straight and narrow path. This metaphor is found a number of times in the Bible. "And he [Josiah, king of Jerusalem] did that which was right in the sight of the Lord, and walked in the ways of David his father, and declined neither to the right hand, nor to the left." (2 Chronicles 34:2) It can also be found in modern popular culture. "But beware of the dark side. Anger, fear, aggression; the dark side of the Force are they. Easily they flow, quick to join you in a fight. If once you start down the dark path, forever will it dominate your destiny, ..." (Yoda, Star Wars)

\section{Protecting Guild TuRf}

I will not use the knife, not even on sufferers from stone, but will withdraw in favor of such men as are engaged in this work.

Here is another negative obligation which proscribes physicians from acting as surgeons. Internists are descended from the ancient order of physicians. Surgeons are descended from the ancient order of barbers. In the ancient era, these two orders were separate and in competition with one another. This portion of the Oath creates a boundary between two spheres of influence. The modern era has almost completely abandoned this boundary. There is now considerable overlap between the practices of internists and surgeons and both groups consider themselves to be physicians.

\section{Sexual Relations with Patients}

Whatever houses I may visit, I will come for the benefit of the sick, remaining free of all intentional injustice, of all mischief and in particular of sexual relations with both female and male persons, be they free or slaves.

The negative obligation forbidding sexual relations between physician and patient is one that remains in full force in the modern era. Most professions consider this boundary to be absolute. It now includes the teacher-student relationship. Notably, neither employers nor politicians consider themselves bound by this negative obligation. Even though the spirit of this part of the Oath is nearly universally accepted by physicians, the wording is tainted by the mention of slavery. Modern revisions of the Hippocratic Oath usually exclude any mention of slavery.

\section{Confidentiality}

What I may see or hear in the course of the treatment or even outside of the treatment in regard to the life of men, which on no account one must spread abroad, I will keep to myself holding such things shameful to be spoken about.

In the ancient era confidentiality between physician and patient was absolute. This is another area in agreement with the Catholic Church. The Church continues to strictly maintain confidentiality, but the modern physician has subordinated doctor-patient confidentiality to public safety. This is one very notable example in which Utilitarian ethics have replaced the principle of non-maleficence. 
The management of Obstructive Sleep Apnea offers a clear example. If a physician discovers through history taking that a patient has fallen asleep while driving, then the patient must agree to stop driving until the problem has been successfully treated. If the patient does not agree, the physician is legally obligated to report the situation to the Department of Motor Vehicles. Although this report would clearly violate doctor-patient confidentiality, the potential harm to the public safety is considered, by government, to outweigh the certain harm to the patient. The government protects the physician from any lawsuit over breach of confidence to enforce its driving regulations.

\section{Concluding Piety}

If I fulfill this path and do not violate it, may it be granted to me to enjoy life and art, being honored with fame among all men for all time to come; if I transgress it and swear falsely, may the opposite of all this be my lot.

This is a common literary device for a pledge. It appears in the Bible as the concluding statement of the 23rd Psalm: "Surely goodness and mercy shall follow me all the days of my life: and I will dwell in the house of the Lord forever." (Psalm 23:6) Modern variations of this conclusion to a pledge often feature retribution by lightning strike. "If I am lying, may lightning strike ... the dog next door." (Garfield)

\section{SUMmARY}

Ancient physicians were granted monopoly privileges by the government to practice their craft and police their ranks. In exchange, physicians agreed to live by a code of ethics as delineated by the Hippocratic Oath. Modern physicians wish to retain their cartel privileges. Medical graduates desire a ceremony recognizing their admission to the ranks of the cartel. Modern Oaths are long on vague promises and short on specific boundaries. An example from a modern Oath taken by students at Texas Tech Health Sciences Center is, "We will serve with compassion while respecting the unique histories, cultures, and beliefs of our patients and their loved ones." The words are chosen mostly to avoid offending any of the students rather than attaching them to a solemn promise.

One of the few parts of the classical Hippocratic Oath that remains accepted in the modern era is the promise to put the interests of the patient above all interests. In an era in which compensation for services rendered is no longer made by the patient, the absence of an Oath replaces the interest of the patient by the interest of the government. The U.S. Postal Service is not held in very high regard by the public, yet its Oath includes the promise, "Neither snow nor rain nor heat nor gloom of night stays these couriers from the swift completion of their appointed rounds." Do physicians really want to promise less than the U.S. Postal Service? The question of who is served by physicians becomes increasingly important as physicians, along with government, craft changes to the U.S. Health Care system.

Author Affiliation: Dr. Gilbert Berdine is a pulmonary physician in the Department of Internal Medicine, TTUHSC.

Received: $10 / 30 / 2014$

Accepted: 1/6/2014

Published electronically: 1/15/2015 